\title{
General anaesthetic management for laser resection of central airway lesions in 85 procedures
}

The perioperative course of 41 patiens undergoing 85 endoscopic laser resections of central ainway lesions under generat anaesthesia was reviewed. The $\mathrm{CO}_{2}$ laser was used in 60 procedures and the Nd:YAC in 25 . Intravenous anaesthesia and Venturi ventilation were utilized for 65 resections; 20 procedures involved predominanty inhalation anaesthesia via the ventilating bronchoscope. Significant intraperative complications included arterial desatwration $\left(\mathrm{SaO}_{2}<90\right.$ per cent) in 26 per cent of procedures, and refractory hypertension requiring vasodilator therapy in 19 per cent. Intravenous anaesthesia was associated with a longer duration of recovery room care and a higher intidence of postoperative respiratory complicarions (delayed exubation, recovery room re-intubation and ventilation, and post-exsubation stridor). Inhalation anaesthesia appeared to simplify the intraoperative management and decrease the incidence, duration and severity of immediate postoperative respiratory camplications.

Although laser resection of central airway lesions using topical anaesthesia has been described, ' many feel that surgical requirements and patient safety are best provided under general anaesthesia. ${ }^{2,3}$ The difficulties of balancing the surgical requirements of airway access, immobility, and obtundation of respiratory reflexes against the need for ventilation, oxygenation, haemodynamic stability and narcosis have been reviewed. ${ }^{2-4}$

Initially the use of the $\mathrm{CO}_{2}$ laser restricted the anaesthetist to an intravenous technique and Venturi ventilation. The

\section{Key words}

EQUIPMENT: laser: $\mathrm{CO}_{2}$, laser: Nd:YAG; sURGERY: bronchoscopy; VENTILATION: Venturi, positive pressure; ANAESTHESIA: inhalation, intravenous.

From the Department of Anaesthesia, Mount Sinai Hospital, University of Toronto, Toronto, Ontario.

Address correspondence to: Dr. Pcrera, Department of Anaesthesia, Mount Sinai Hospital, 600 University Avenue, Toronto, Ontario, MSG 1 X.5. advent of the Nd:YAG laser, which is transmissible by fibre-optics, enabled the administration of inhalation anaesthesia via conventional ventilating systems. Controversy exists as to which anaesthetic and ventilation techniques are more suitable. ${ }^{2-5}$

This report summarizes our anaesthetic experience with 85 procedures involving both laser types, and outlines the perioperative complications encountered with intravenous and inhalation techniques.

\section{Methods and Results}

\section{Data collection}

The hospital records of all patients undergoing laser resection of obstructing airway lesions were reviewed by the authors to determine the patients' age, diagnoses, site of obstruction, related medical problems, and the nature of any previous therapy related to the airway pathology.

From the andesthetic record we determined the type of laser used, the mode of induction, maintenance and the duration of general anaesthesia, and the method of ventilation. Documentation of the following intraoperative problems was noted: $\mathrm{SaO}_{2}<90$ per cent, clinical difficulty with ventilation and/or $\mathrm{PaCO}_{2}>6 \mathrm{kPa}$ (45 $\mathrm{mmHg}$ ), hypertension necessitating vasodilator therapy, haemorrhage, and any arrhythmias requiring treatment.

The recovery room record was reviewed to identify delayed extubation (any patient not extubated within 15 minutes of arrival) and the incidence and duration of postoperative ventilation. The presence of postextubation stridor, wheeze, or other respiratory distress requiring specific treatment (heliox, racemic epinephrine, or reintubation) was noted. The duration of recovery room observation was calculated.

The date and cause of any postoperative death prior to hospital discharge were noted.

\section{Patient population}

Between March 1984 and June 1986, 41 patients with symptomatic airway obstruction underwent 85 laser 
resections ( $1-10$ procedures per patient). The average age was $59 \pm 13$ years (range: $31-84$ years). Carcinoma of the lung accounted for 23 of 31 diagnoses of malignancy. Sixteen patients had had previous thoractomies, including four pneumonectomies. Benign diagnoses in ten patients included four bronchial tumours, one supraglottic stricture, three tracheal strictures, and two bronchial strictures (one following lung transplant). Three patients were ventilatordependent and five had tracheostomies in situ. Four patients had stable coronary artery disease, and two of these patients had sustained a remote myocardial infarction.

All patients were admitted to hospital. Preoperative evaluation included a chest $x$-ray, ECG, arterial blood gases, and fibre-optic bronchoscopy under local anaesthesia.

\section{Conduct of anaesthesia}

Routine preoperative medication was limited to intramuscular glycopyrrolate $(0.2-0.4 \mathrm{mg})$. Less symptomatic patients received sublingual lorazepan in addition. Nebulized salbutamol was given immediately prior to each procedure.

All patients were monitored with an EKG, automatic blood pressure cuff, peripheral nerve stimulator and a pulse oximeter. Previously placed arterial catheters were utilized to monitor blood pressure on three occasions for ventilator-dependent patients.

All anaesthetics were administered by a staff anaesthetist assisted by a resident and/or a specially-trained respiratory therapist. Appropriate precautions against the known laser hazards to patients and operating room personnel were strictly observed. ${ }^{6-8.11}$

Patients were pre-oxygenated with 100 per cent $\mathrm{O}_{2}$. Fentanyl (1-2 $\left.\mu \mathrm{g} \cdot \mathrm{kg}^{-1}\right)$, diazepam (2.5-5.0 $\left.\mathrm{mg}\right)$ and/or lidocaine $\left(1-1.5 \mathrm{mg} \cdot \mathrm{kg}^{-1}\right)$ were given intravenously. General anaesthesia was induced with thiopentone IV on all but two occasions: one patient with severe stridor was induced with halothane via mask and a second with enflurane via tracheostomy tube. Once controlled manual ventilation was established paralysis was induced with succinylcholine IV and maintained with either a 0.2 per cent succinylcholine infusion or with intermittent nondepolarizing neuromuscular blockers. Patients were categorized according to the technique of maintenance of anaesthesia as either Group I (intravenous only) or Group II (predominantly inhalation).

GROUP I

Maintenance consisted of thiopentone IV, either intermittently or by a 0.4 per cent infusion, supplemented by small doses of fentanyl and/or diazepam. Patients were ventilated through a rigid bronchoscope (Wolf 8.0) adapted for side-arm Venturi ventilation with either a 50:50 oxygen-nitrogen mixture or with 100 per cent oxygen. Bilateral side vents on the bronchoscope permitted ventilation to the contralateral lung during endobronchial resection.

\section{GROUP 11}

The anaesthetic machine was modified to deliver volatile agents in a nitrous-oxide free, air-oxygen mixture by splicing an air-oxygen blender (Bird $3 \mathrm{M}$ ) into the oxygen supply hose between the wall outlet and the anaesthetic machine. The nitrous-oxide - oxygen mixer dial (MDM) was fixed in the " 100 per cent oxygen" position and the $\mathrm{FJO}_{2}$ controlled by the up-stream blender. The $\mathrm{FIO}_{2}$ was monitored with an oxygen analyser in the inspiratory limb of the circle system. Intermittent positive pressure breathing was achicved via a rigid ventilating bronchoscope with side-ann connection to the semi-closed circleabsorber system. During laser firing, the $\mathrm{FIO}_{2}$ was lowered to 0.4 to minimize the combustion hazard. $\mathrm{Nd}$ Y AG laser beams were transmitted via an optical fibre passed through the suction channel of the flexible fibreoptic bronchoscope (Olympus BF-IT 10) which in tum was introduced through the ventilating bronchoscope (Figure).

In both Groups, patients were left briefly apnoeic during laser firing to minimize airway motion. Airway fumes were aspirated via an endotracheal suction catheter taped to the external surface of the rigid bronchoscope. Intraoperative hypertension refractory to deepening the level of anaesthesia was treated by an infusion of nitroglycerin $\left(100-200 \mu \mathrm{g} \cdot \mathrm{ml}^{-1}\right)$. Significant arterial oxygen desaturation (less than 90 per cent) was treated by cessation of laser firing, withdrawal of the rigid broncho-

TABLE I Intraoperative course and complications

\begin{tabular}{|c|c|c|}
\hline & Group I & Group $/ I$ \\
\hline Method of anaesthesia & Intravenous & Inhaiation \\
\hline Method of ventilation & Venturi & Conventional \\
\hline Number of treatments & 65 & 20 \\
\hline \multicolumn{3}{|l|}{ Laser type } \\
\hline $\mathrm{CO}_{2}$ & 56 & 4 \\
\hline Nd:YAG & 9 & 16 \\
\hline Duration of anaesthesia (hrs) & $1.1=0.4$ & $1.2 \pm 0.5$ \\
\hline \multicolumn{3}{|l|}{ Complications (\%) } \\
\hline $\mathrm{SaO}_{2}<90 \%$ & $16(25 \%)$ & $6(30 \%)$ \\
\hline $\mathrm{SaO}_{2}<80 \%$ & $8(12 \%)$ & $0(0)$ \\
\hline $\mathrm{PaCO}_{2}>6 \mathrm{kPa}$ & $2(3 \%)$ & $0(0)$ \\
\hline Hypertension* & $13(20 \%)$ & $3(15 \%)$ \\
\hline Hypotension* & $3(5 \%)$ & $1(5 \%)$ \\
\hline Arrthythmias* & 1 & 1 \\
\hline Awareness & 1 & 0 \\
\hline
\end{tabular}

Duration expressed as mean $\pm 5 \mathrm{D}$.

*Requiring treatment. 


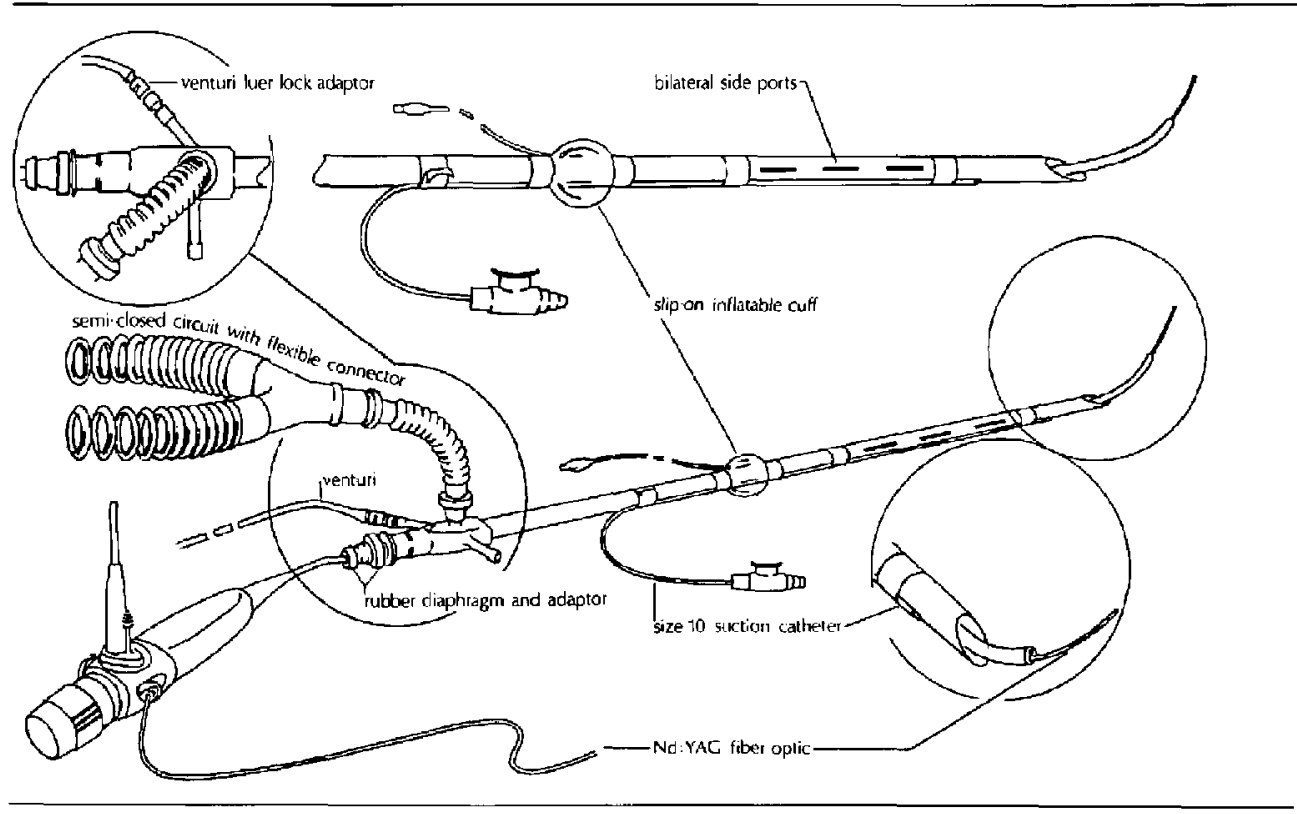

FIGURE Ventilating bronchoscope and attachments for Nd:YAG laser resection.

scope into the trachea if indicated (for $\mathrm{CO}_{2}$ laser), ventilation with an increased $\mathrm{FrO}_{2}$ and if necessary, re-intubation with a cuffed endotracheal tube followed by ventilation with 100 per cent oxygen.

\section{Postoperarive management}

At the end of the procedure, patients were re-intubated with a cuffed endotracheal tube for airway toilet and ventilated with 100 per cent oxygen until recovery of neuromuscular function and protective airway reflexes was satisfactory. Patients were extubated whenever possible in the operating room. Except for the three ventilatordependent patients who were retumed to the ICU, all patients were observed in the recovery room for a minimum of one hour, during which time hurnidified oxygen was administered and portable chext $x$-rays obtained.

\section{Complications}

Table I summarizes the intraoperative complications. There were no intraoperative deaths, pneumothoraces, nor episodes of massive haemorrhage; one minor combustion event involved laser vaporization of the distal tip of the suction catheter, without adverse sequelae.

Significant desaturation complicated about 26 per cent of procedures. Our impression was that desaturation episodes were more frequent, more severe, and were slower to respond to treatment during periods of Venturi ventilation. Of the six Group II patients who desaturated only two did so during periods of conventional ventilation; a third occurred during a prolonged attempt at intubation and the remaining three desaturated only during brief periods of Venturi ventilation. No Group II patient desaturated to less than 80 per cent, whereas 12 per cent of Group I patients desaturated to levels of $70-79$ per cent.

Only two patients, both in Group 1 , were noted to present clinical difficulty with ventilation. Both episodes were associated with oxygen desaturation, and arterial blood gases in each instance confirmed a $\mathrm{PaCO}_{2}$ of 10.3 $\mathrm{kPa}(77 \mathrm{mmHg}$ ).

Vasodilator therapy was required for refractory hypertension in about 19 per cent of procedures, regardless of anaesthctic tcchnique. However, our impression was that blood pressure control was simpler using an inhalation technique. Hypotension was an infrequent complication

Only two significant arthythmias were documented: one Group I patient developed ventricular bigeminy following tracheal instillation of a 1:500,000 epinephrine solution for haemostasis, and one Group II patient developed frequent ventricular extra-systoles under halo- 
TABLE Il Recovery room complications

\begin{tabular}{|c|c|c|}
\hline & $\begin{array}{l}\text { Group I } \\
\text { (Intravenous) }\end{array}$ & $\begin{array}{l}\text { Group /I } \\
\text { (Inhalation) }\end{array}$ \\
\hline Delayed extubation* & $36 \%(22 / 61)$ & $13 \%(2 / 15)$ \\
\hline Duration (hrs) & $0.25-3.25$ & $0.75-1.5$ \\
\hline Prolonged ventilationt & $22 \%_{(14 / 6.3)}$ & $5 \%(1 / 19)$ \\
\hline Duration (hrs) & $0.25-2.5$ & 0.75 \\
\hline Postextubation stridort & $18 \%(11 / 61)$ & $7 \%(1 / 15)$ \\
\hline Re-intubation & $10 \%(6 / 61)$ & $(0 / 15)$ \\
\hline Pulmonary oedema & 1 & 0 \\
\hline Required naloxone & 1 & 0 \\
\hline $\begin{array}{l}\text { Total incidence - one } \\
\text { or more complicalions }\end{array}$ & $5[\%(32 / 63)$ & $16 \%(3 / 19)$ \\
\hline $\begin{array}{l}\text { Total times in RR (hrs) } \\
\text { (range) }\end{array}$ & $\begin{array}{l}2.2=1.2 \\
(1.0-6.0)\end{array}$ & $\begin{array}{l}1.5 \pm 0.5 \\
(1.0-3.0)\end{array}$ \\
\hline
\end{tabular}

*No tube/tracheostomy pręop.

tNo ventilation preop.

$¥$ Requiring heliox, racemic epinephrine, salbutamol, or re-intubation. stime expressed as mcan $\pm S D$.

thane anaesthesia. Both responded to IV lidocaine. One Group I paticnt reported intraopcrative awareness.

Table Il outlines the postoperative respiratory complications of the 82 patients admitted to the recovery room. Compared to Group II, Group 1 had a higher incidence of delayed extubation, prolonged ventilation, posi-extubation stridor and subsequent re-intubation. The duration of postoperative airway and ventilatory support was generally longer in Group 1. One Group I patient required 20 hours of postoperative ICU ventilation after developing pulmonary oedema. The average recovery room stay was greater in Group 1 than in Group II. The longest stay was in Group I. No paticnt required re-intubation subsequent to discharge from the recovery room.

Four patients died within seven days of surgery, all following unsuccessful palliation of malignant disease. None of these deaths was felt to be a surgical or an anaesthetic complication. One perioperative myocardial infarction was identified in a Group I patient with known coronary artery disease. His procedure had been complicated by several episodes of arterial desaturation during Venturi ventilation. Two days following surgery, he developed acute congestive heart failure, and ultimately expired of complications after several weeks in the ICU.

\section{Discussion}

The increasing utilization of the Nd:YAG laser for the resection of central airway lesions provides the anaesthetist with options in anaesthetic technique. Ours is an uncontrolled retrospective report, not designed to rigorously compare intravenous with inhalation anaesthesia, nor Venturi with conventional ventilation. Increased surgical and anaesthetic experience with time may well have contributed to the lower complication rates in our Group II patients. Nonetheless, we were impressed with the strong association between intravenous - Venturi anaesthesia and recovery room complications. Our most serious complications - pulmonary oedema, myocardial infarction and postoperative re-intubation - all occurred in our Group I patients.

Nd:YAG resections can be performed through a cuffed endotracheal tube; ${ }^{2}$ however, we have abandoned this technique. The rigid bronchoscope enables better surgical access for control of bleeding, suctioning of blood and secretions, and for piecemeal removal of tumour by forceps. $3,6,9-11$

The use of Venturi ventilation can facilitate the rapid dispersal of airway fumes, but carries the risk of pneumothorax, excessive airway motion, and distal embolization of blood, secretions and tumour fragments. For Nd:YAG resections we now restrict the use of Venturi ventilation to brief periods following the actual laser firing if required, without having to resort to intravenous maintenance of anaesthesia. Airway motion during laser discharge is elininated by pemitting brief periods of apnoea.

Conventional ventilation during these procedures has been reported to result in a higher mean $\mathrm{PaCO}_{2}$ compared to Venturi ventilation. ${ }^{2-5}$ Most studies report a modest hypercarbia only $\left(\mathrm{PaCO}_{2} 6.0-8.0 \mathrm{kPa}, 45-60 \mathrm{mmHg}\right)$. We have had no clinical problems using the ventilating bronchoscope, but we did experience ventilation difficulty with two patients using the Venturi system. We do feel, however, that the potential for sudden life-threatening airway obstruction is high regardless of ventilation technique used.

Like Duckett et al., ${ }^{4}$ we encountered a high incidence of intraoperative arterial desaturation. Oxygen saturation in many Venturi-ventilated patients recovered only after re-intubation with an endotracheal tube, whereas conventionally ventilated patients responded quickly to a simple increase in the $\mathrm{FIO}_{2}$ in almost all instances. The entrainment of room air during Venturi ventilation makes it difficult to achieve a high $\mathrm{F}_{1} \mathrm{O}_{2}$, even when using a 100 per cent oxygen source.

We have found the pulse oximeter to be a reliable and essential monitor for the early detection and correction of hypoxaemia. Arterial blood gas analysis is less useful due to the time delay involyed. We do not routinely use indwelling arterial catheters, as many of these patients require multiple procedures over short periods of time.

Endoscopic laser resections predispose to intraoperative arrhythmias dure to prolonged airway instrumentation, hypoxaemia, hypercarbia, haemodynamic instability, topical administration of epinephrine-containing solutions, and halothane use. Our low incidence of arrhythmias was probably a consequence of the liberal use 
of IV lidocane, administered for the suppression of reflex coughing and bronchospasm.

A major disadvantage of intravenous anaesthesia lies in the potential for prolonged recovery, particularly following lengthy procedures. ${ }^{3}$ Although our resection times averaged only about 15 minutes, associated diagnostic, therapeutic and teaching procedures lengthened total anaesthetic time to over one hour. Prolonged somnolence following intravenous anaesthesia was a major contributing factor to our high incidence of postoperative respiratory complications. Like Warner et al. ${ }^{5}$ we have found that inhalation anaesthesia has almost abolished the need for postoperative airway and ventilatory support.

Although none of our patients required re-intubation following discharge from the recovery room, this complication due to reactive airway oedema has been described ${ }^{5}$ Despite relief of obstruction, deterioration in gas exchange is common following laser surgery ${ }^{2}$ and close monitoring for 24 hours after extensive resections is advisable.

In summary, we conclude that laser resection of central airway lesions is associated with a high incidence of perioperative cardiac and respiratory instahility. We propose that inhalation anaesthesia provides for a smoother intraoperative course, and may decrease the incidence and severity of recovery room respiratory complications.

\section{Acknowledgements}

We express our gratitude to Dr. Melvyn Goldberg and Dr. Robert Ginsberg from the Department of Surgery, Division of Thoracic Surgery, Mount Sinai Hospital, Toronto, for their help and advice.

\section{References}

1 Dumon JF, Reboud E, Garbe Let al. Treatment of tracheobronchial lesions by laser photoresection. Chest 1982; 81: 278-84.

2 Brutinel WM, McDougul JC, Correse DA. Bronchoscopic therapy with neodymium-yttrium-aluminum-garnet laser during intravenous anaesthesia. Chest 1983;84: 518-21.

3 Sia RL, van Overbeek JJM, Rashkovsky $O M$. Three years' experience with the Groningen Nd:YAG laser caagulation technique. Anaesthesia 1985; 40:904-6.

4 Duckett JE, McDonnell TJ, Unger M, Parr GVS. General anaesthesia for Nd:YAG laser resection of obstructing endobronchial tumours using the rigid bronchoscope. Can Anaesth Soc J 1985; 32: 67-72.

5 Warner ME, Warner MA, Leonard F. Anesthesia for neodymiunl-YAG (Nd:YAG) laser resection of major airway obstructing tumors. Anesthesiology 1984; 60: $230-2$.
6 Kvale PA. Eichenvorns MS. Radke JR, Miks V. YAG lase photoresection of lesions obstructing the central airways. Chest 1985; 87: 283-8.

7 Hermens JM, Bennett MJ, Hirschman CA. Anesthesia for laser surgery. Anesth Analg 1983; 62: 218-29.

8 Edelist $G$. Anaesthesia for endoscopy and laser surgery. Can Anaesth Soc J 1984; 31 : \$1-4.

9 Vourc'A $G$, Fischier $M$, Michon F, Melchior JC, Seigneur $F$. Manual jet ventilation $v$. high frequency jet ventilation during laser resection of tracheo-bronchial stenosis. Br J Anaesth 1983; 55: 973-5.

10 Vourc'h $G$, Fischler $M$, Personne $C$. Anesthetic management during Nd:YAG laser resection for major obstructing tracheobronchial tumors (Letrer). Anesthesiology 1984; 61: 636-7.

11 Dumon JF, Shapshay $S$, Bourcereau J et al. Principles for safety in application of neodymium-YAG laser in bronchology. Chest 1984; 86: 163-8.

\section{Résumé}

On a revisé le déroulement pêriopératoire chez 41 patients subissant sous anesthesie générale, des rèsections de lésions des voics respiratoires, par endoscopie au laser. Le laser $\mathrm{CO}_{2}$ a été utilisé dars 60 des interventions et le Nd:YAG dans 25. L'anesthêsie intraveineuse et la ventilation par Venturi ont été utilisées pour 65 résections; l'anesthésie par inhalation par bronchoscope ventilatoire était prédominante dans 20 interven. fions. Parmi les complications intraopératoires significatives on retrouvait une désaturisation artérielle $\left(\mathrm{SaO}_{2}<90\right.$ pour cent) dans 26 pour cent des interventions, et une hypertension réfractaire nécessitant une thérapie dans 19 pour cent des interventions. L'anesthésie intraveineuse étail associée à un rétablisse. ment plus long en salle de réveil et à une incidence plus élevée dans les complications respiratoires postopératoires lexuba. tion retardée, réintubation et ventilation en salle de réveil, et stridor postexubation). L'anesthésie par inhalation semblait simplifier la conduitc intraopúratoire et diminuer l'incidence, la durée et la gravité des complications respiratoires en période postopératoire immédiate. 